\title{
Long non-coding RNA TUG1 as a potential prognostic biomarker in human cancers: a meta-analysis
}

\author{
Peng-Ju Ma ${ }^{1,{ }^{*}}$, Qing-Kai Guan ${ }^{1,{ }^{*}}$, Lei Meng ${ }^{1}$, Nan Qin ${ }^{1}$, Jia Zhao ${ }^{1}$ and Bao-Zhe Jin ${ }^{1}$ \\ ${ }^{1}$ Department of Neurosurgery, The First Affiliated Hospital of Xinxiang Medical University, Xinxiang 453000, Henan Province, \\ People's Republic of China \\ *These authors have contributed equally to the work \\ Correspondence to: Bao-Zhe Jin, email: jinbaozhe2016@163.com \\ Keywords: TUG 1, neoplasms, prognosis, metastasis, meta-analysis \\ Received: March 29, $2017 \quad$ Accepted: May 29, $2017 \quad$ Published: July 08, 2017 \\ Copyright: Ma et al. This is an open-access article distributed under the terms of the Creative Commons Attribution License 3.0 \\ (CC BY 3.0), which permits unrestricted use, distribution, and reproduction in any medium, provided the original author and source \\ are credited.
}

\section{ABSTRACT}

LncRNA taurine upregulated gene 1 (TUG1) is reportedly dysregulated in various cancers. We performed this meta-analysis to clarify the usefulness of TUG1 as a prognostic marker in malignant tumors. The PubMed, Medline, OVID, Cochrane Library, and Web of Science databases were searched from inception to Jan 11, 2017. Hazard ratios (HRs) and $95 \%$ confidence intervals (CIs) were calculated to explore the relationship between TUG1 expression and overall survival (OS). Odds ratios (ORs) were calculated to assess the association between TUG1 expression and pathological parameters. Thirteen original studies covering 1,274 cancer patients were included in this meta-analysis. The pooled HR suggested that high TUG1 expression correlated with poor OS (pooled HR=1.41, 95\% CI: 1.01-1.98) in cancer types other than nonsmall cell lung cancer. TUG1 expression was also related to distant metastasis (OR=3.24, 95\% CI: 1.18-8.93), large tumor size (OR=4.07, 95\% CI: $1.08-15.28)$ and advanced tumor stage ( $O R=3.45,95 \% \mathrm{CI}: 2.19-5.44)$. Begg's funnel plot and Egger's test showed no evidence of obvious asymmetry for overall survival or tumor stage. Thus high TUG1 expression appears predictive of poor OS, distant metastasis, advanced tumor stage and large tumor size. This suggests TUG1 expression could serve as a biomarker for poor prognosis in cancers.

\section{INTRODUCTION}

According to the American Cancer Society, approximately 1.7 million new cancer cases and 600 thousand cancer deaths are projected to occur in American in 2017 [1]. Furthermore, it has been reported that 8.2 million people die from cancers and 14.1 million people are diagnosed with cancer in 2012 worldwide [2]. Despite recent advances in clinical treatment, cancer continues to be a leading cause of death worldwide, owing to delayed diagnosis, poor prognosis, recurrence and development of resistance by cancer cells. Therefore, efforts to develop new prognostic markers should be made to help modify clinical application in cancers.

Long noncoding RNAs (lncRNAs) are nonprotein-coding RNA molecules longer than 200 nucleotides. According to the Encyclopedia of DNA Elements (ENCODE) project, the transcripts cover 62$75 \%$ of our genome, among which are mostly noncoding RNAs [3]. LncRNAs have many important functions in disease, including epigenetic regulation and transcriptional and posttranscriptional regulation [4]. Recently, dysregulation of lncRNAs has bee reported in various types of cancer [5-8]. Some lncRNAs play a vital role in cancer progression, affecting proliferation, invasion and metastasis [9-10]. This suggests LncRNAs may be a useful marker of cancer prognosis and metastasis [11].

In 2005, IncRNA Taurine Upregulated Gene 1 (TUG1) was initially identified as a transcript up-regulated by taurine in mouse retinal cells [12]. TUG1 is located at chromosome 22q12. Recently, more and more scientists 
have found that TUG1 might play important roles in cancer proliferation and metastasis, and TUG1 expression may have a relationship with prognosis and metastasis of human cancers [13]. However, most studies reported so far are limited in discrete outcome and sample size. Up to date, no meta-analysis has been performed to examine the relationship between TUG1 and the relevant clinical outcomes as well as clinicopathological parameters and survival. Therefore, we performed this meta-analysis to investigate whether TUG1 could serve as a molecular marker for prognosis prediction in human cancers.

\section{RESULTS}

\section{Study characteristics}

The detailed screening process is shown in detail in Figure 1. According to the inclusion and exclusion criteria, thirteen studies and 1,274 patients were included in the meta-analysis [14-26]. Additionally, the characteristics of the 13 studies included in the present meta-analysis are summarized in Table 1. The subject number of 13 studies ranged from 33 to 218, with a mean sample size of 98 . Twelve of the thirteen studies were conducted in China whereas one study was from Czech Republic and were published between 2014 and 2017. Among the thirteen studies, two focused on non-small cell lung cancer [20, 24], and one each on hepatocellular carcinoma [14], muscleinvasive bladder cancer [15], esophageal squamous cell carcinoma [16], ovarian cancer [17], glioma [18], breast cancer [19], osteosarcoma [21], small cell lung cancer [22], colorectal cancer [23], renal cell carcinoma [25], gastric cancer [26]. TUG1 expression was measured in cancerous specimens. All of the diagnoses of DM, tumor size and tumor stage were all dependent on the pathology. The reference gene of TUG1 in these studies were found to be inconsistent, including GAPDH [14, 16-25], RNU48 [15] and $\beta$-actin [26]. The Newcastle-Ottawa Scale (NOS) confirmed that all studies were of good quality (Table 2).

\section{Association between the TUG1 expression level and $\mathrm{OS}$}

We performed a cumulative meta-analysis to assess the function of TUG1 for overall survival (OS) in patients with cancer. Additionally, nine included studies with 995 patients reported the relationship between OS and TUG1. The random effects model was used due to significant heterogeneity $\left(\mathrm{I}^{2}=82 \%, \mathrm{P}_{\mathrm{Q}}=0.000\right)$. Due to the presence of heterogeneity, subgroups were analyzed based on cancer type (NSCLC or other cancer). A significant association was observed between TUG1 and OS in other cancer patients (pooled HR=1.41, 95\% CI: 1.01-1.98; Figure 2). Furthermore, the subgroups were analyzed based on the cancer type and revealed a significant association between TUG1 and OS in NSCLC (HR=0.49, 95\% CI: 0.34-0.71).
This result demonstrated that a high expression of TUG1 might be correlated with a shorter OS in other types of cancer that excluded NSCLC. Thus, we found that TUG1 was an independent factor of OS among patients with cancer.

\section{Association between the TUG1 expression level and DM}

Three hundred twenty patients with cancer from 3 eligible studies were collected and analyzed. The random effects model was used for significant heterogeneity $\left(\mathrm{I}^{2}=55.7 \%, \mathrm{P}_{\mathrm{Q}}=0.105\right)$. The odds ratio (OR), expressed as the high TUG1 expression group versus low TUG1 expression group was 3.24 (95\% CI: $1.18-8.93, \mathrm{P}=0.02$; Figure 3 ). According to the result, there was a significant difference between the two groups in the DM incidence. Additionally, the results demonstrated that a high expression of TUG1 significantly predicted a higher tendency to develop DM in patients with cancer.

\section{Association between the TUG1 expression level and tumor size}

The correlations between TUG1 expression and tumor size are presented in Figure 4. Five studies with 511 patients declared the association between the TUG1 expression levels and number of cancer patients with lager tumor size. There was significant heterogeneity in these studies, and the random-effects model was used $\left(\mathrm{I}^{2}=89.2 \%, \mathrm{P}_{\mathrm{Q}}=0.000\right)$. The analysis showed a pooled $\mathrm{OR}=4.07$ (95\% CI: 1.08-15.28, $\mathrm{P}=0.04$; high versus low TUG1 expression; Figure 4). As a result, the patients with lager tumor size were significantly increased in the high TUG1 expression group. The result revealed that patients with a high TUG1 expression level in tumor tissues may indicate an increased probability of lager tumor size.

\section{Association between the TUG1 expression level and tumor stage}

Eight hundred twenty-six patients in nine eligible studies were included to detect the relationship between the TUG1 expression levels and tumor stage in this metaanalysis. The random effects model was used for significant heterogeneity $\left(\mathrm{I}^{2}=47.6 \%, \quad \mathrm{P}_{\mathrm{Q}}=0.054\right)$. A significant connection was found between a high TUG1 expression level and high tumor stage in cancer patients (pooled $\mathrm{OR}=$ 3.45, 95\% CI: 2.19-5.44, $\mathrm{P}<0.00001$; Figure 5).

From the analysis results, the tumor stage was significantly increased in the high TUG1 expression group compared with that in the low TUG1 expression group, and the results demonstrated that a high expression of TUG1 significantly increased the risk of high tumor stage. 
Table 1: The basic information and data of all included studies in the meta-analysis

\begin{tabular}{|c|c|c|c|c|c|c|c|c|c|c|c|c|c|c|c|}
\hline \multirow[t]{3}{*}{ Study } & \multirow[t]{3}{*}{ Year } & \multirow[t]{3}{*}{ Region } & \multirow{3}{*}{$\begin{array}{l}\text { Tumor } \\
\text { type }\end{array}$} & \multirow{3}{*}{$\begin{array}{l}\text { Sample } \\
\text { size }\end{array}$} & \multicolumn{6}{|c|}{ TUG1 expression } & \multirow{3}{*}{$\begin{array}{l}\text { Analysis } \\
\text { (OS) }\end{array}$} & \multirow{3}{*}{$\begin{array}{c}\text { HR(95\% CI) } \\
\text { high / low }\end{array}$} & \multirow{3}{*}{$\begin{array}{l}\text { Reference } \\
\text { gene }\end{array}$} & \multirow[t]{3}{*}{ NOS } & \multirow[t]{3}{*}{ Method } \\
\hline & & & & & \multirow{2}{*}{\multicolumn{3}{|c|}{ Total DM HS }} & \multicolumn{3}{|c|}{ Low } & & & & & \\
\hline & & & & & & & & Total & DM & HS & & & & & \\
\hline Huang ${ }^{[14]}$ & 2015 & China & $\mathrm{HCC}$ & 77 & 47 & - & 33 & 30 & - & 6 & - & - & GAPDH & 7 & PCR \\
\hline $\operatorname{Iliev}^{[15]}$ & 2016 & Czech & MIBC & 47 & 26 & - & - & 21 & - & - & Multivariate & $2.54(1.13-5.74)$ & RNU48 & 7 & PCR \\
\hline Jiang $^{[26]}$ & 2016 & China & ESCC & 218 & 109 & - & 64 & 109 & - & 50 & Multivariate 1 & $1.403(1.012-1.946)$ & GAPDH & 8 & PCR \\
\hline Kuang ${ }^{[17]}$ & 2016 & China & $\mathrm{OC}$ & 62 & 33 & - & 25 & 29 & - & 12 & - & - & GAPDH & 7 & PCR \\
\hline $\mathrm{Li}^{[18]}$ & $2016 a$ & China & Glioma & 120 & 60 & - & - & 60 & - & - & Multivariate & $0.57(0.34-0.96)$ & GAPDH & 7 & PCR \\
\hline $\mathrm{Li}^{[19]}$ & $2016 b$ & China & $\mathrm{BC}$ & 100 & 55 & 34 & 44 & 45 & 8 & 16 & - & - & GAPDH & 7 & PCR \\
\hline $\operatorname{Lin}^{[20]}$ & 2016 & China & NSCLC & 89 & 31 & - & - & 58 & - & - & Multivariate & $0.77(0.27-2.22)$ & GAPDH & 7 & PCR \\
\hline $\mathrm{Ma}^{[21]}$ & 2015 & China & OSC & 76 & 41 & - & 9 & 35 & - & 3 & Multivariate & $2.78(1.29-6.00)$ & GAPDH & 8 & PCR \\
\hline $\mathrm{Niu}^{[22]}$ & 2017 & China & SCLC & 33 & 16 & - & 12 & 17 & - & 5 & Multivariate & $1.61(0.52-4.99)$ & GAPDH & 7 & PCR \\
\hline $\operatorname{Sun}^{[23]}$ & 2016 & China & CRC & 120 & 71 & 18 & 36 & 49 & 7 & 15 & Multivariate & $2.15(1.29-3.58)$ & GAPDH & 8 & PCR \\
\hline Zhang $^{[24]}$ & 2014 & China & NSCLC & 192 & 96 & - & - & 96 & - & - & Multivariate & $0.46(0.31-0.68)$ & GAPDH & 7 & PCR \\
\hline Zhang $^{[25]}$ & $2016 a$ & China & $\mathrm{RCC}$ & 40 & 31 & - & 9 & 9 & - & 2 & - & - & GAPDH & 7 & PCR \\
\hline Zhang ${ }^{[26]}$ & $2016 b$ & China & $\mathrm{GC}$ & 100 & 50 & 3 & 28 & 50 & 2 & 15 & Multivariate 1 & $1.066(1.023-1.112)$ & $\beta$-actin & 8 & PCR \\
\hline
\end{tabular}

Note: The dashes represent no data.

HCC, hepatocellular carcinoma; MIBC, muscle-invasive bladder cancer; ESCC, esophageal squamous cell carcinoma; OC, ovarian cancer; BC, breast cancer; NSCLC, non-small cell lung cancer; OSC, osteosarcoma; SCLC, small cell lung cancer; CRC, colorectal cancer; RCC, renal cell carcinoma; GC, gastric cancer; DM, distant metastasis; HS, high stage; OS, overall survival; HR, hazard ratio; NOS, Newcastle-Ottawa Scale.

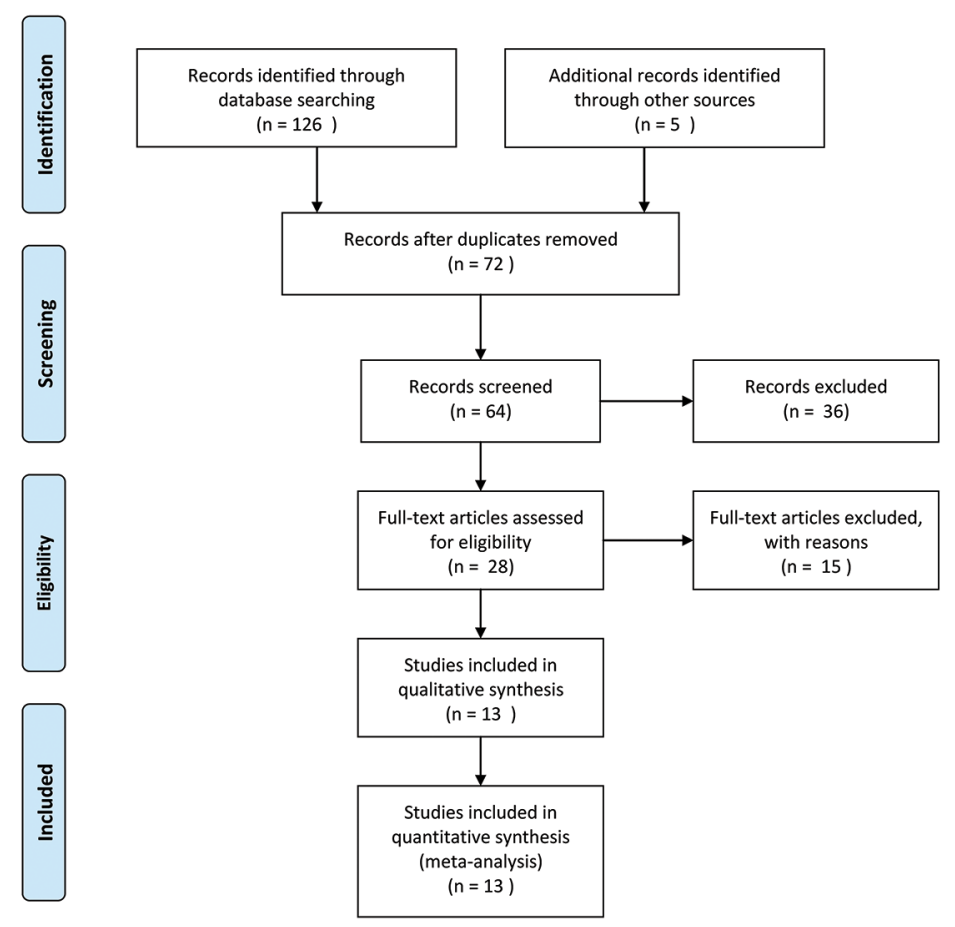

Figure 1: Flowchart showing the steps of literature search and selection criteria for the meta-analysis. 
Table 2: Study quality was assessed according to the Newcastle-Ottawa Scale

\begin{tabular}{|c|c|c|c|c|c|c|c|c|c|}
\hline Author & Country & $\begin{array}{l}\text { Adequate } \\
\text { of case } \\
\text { definition }\end{array}$ & $\begin{array}{l}\text { Representativeness } \\
\text { of the cases }\end{array}$ & $\begin{array}{c}\text { Selection } \\
\text { of } \\
\text { controls }\end{array}$ & $\begin{array}{c}\text { Definition } \\
\text { of } \\
\text { controls }\end{array}$ & $\begin{array}{l}\text { Comparability } \\
\text { of cases and } \\
\text { controls }\end{array}$ & $\begin{array}{l}\text { Ascertainment } \\
\text { of exposure }\end{array}$ & $\begin{array}{c}\text { Same } \\
\text { method of } \\
\text { ascertainment }\end{array}$ & $\begin{array}{l}\text { Non- } \\
\text { response } \\
\text { rate }\end{array}$ \\
\hline Huang ${ }^{[14]}$ & China & $\star$ & $\star$ & $\star$ & NA & $\star \star$ & $\star$ & $\star$ & NA \\
\hline Iliev $^{[15]}$ & Czech & $\star$ & $\star$ & $\star$ & NA & $\star \star$ & $\star$ & $\star$ & NA \\
\hline Jiang $^{[26]}$ & China & $\star$ & $\star$ & $\star$ & $\star$ & $\star \star$ & $\star$ & $\star$ & NA \\
\hline Kuang ${ }^{[17]}$ & China & $\star$ & $\star$ & $\star$ & NA & $\star \star$ & $\star$ & $\star$ & NA \\
\hline $\mathrm{Li}^{[18]}$ & China & $\star$ & $\star$ & $\star$ & NA & $\star \star$ & $\star$ & $\star$ & NA \\
\hline $\mathrm{Li}^{[19]}$ & China & $\star$ & $\star$ & $\star$ & NA & $\star \star$ & $\star$ & $\star$ & NA \\
\hline $\operatorname{Lin}^{[20]}$ & China & $\star$ & $\star$ & $\star$ & NA & $\star \star$ & $\star$ & $\star$ & NA \\
\hline $\mathrm{Ma}^{[21]}$ & China & $\star$ & $\star$ & $\star$ & NA & $\star \star$ & $\star$ & $\star$ & NA \\
\hline $\mathrm{Niu}^{[22]}$ & China & $\star$ & $\star$ & $\star$ & NA & $\star \star$ & $\star$ & $\star$ & NA \\
\hline $\operatorname{Sun}^{[23]}$ & China & $\star$ & $\star$ & $\star$ & NA & $\star \star$ & $\star$ & $\star$ & NA \\
\hline Zhang ${ }^{[24]}$ & China & $\star$ & $\star$ & $\star$ & NA & $\star \star$ & $\star$ & $\star$ & NA \\
\hline Zhang $^{[25]}$ & China & $\star$ & $\star$ & $\star$ & NA & $\star \star$ & $\star$ & $\star$ & NA \\
\hline Zhang ${ }^{[26]}$ & China & $\star$ & $\star$ & $\star$ & $\star$ & $\star \star$ & $\star$ & $\star$ & NA \\
\hline
\end{tabular}

Notes: The quality of the article is through the number of $\operatorname{stars}\left({ }^{*}\right)$. Through the selection and exposure categories, each numbered item gets a star at most. A maximum of two stars can be given for comparability. NA: not available

\section{Publication bias}

Next, Begg's funnel plot and Egger's test were constructed to evaluate publication bias. The results showed no evidence of obvious asymmetry for overall survival $(P>|t|=0.722$, Figure 6). Similarly, there was no evidence for significant publication bias in terms of tumor stage $(P>|t|=0.192$, Figure 7).

\section{DISCUSSION}

Cancer remains a serious threat to human health, and the incidence of cancer has increased gradually in recent years [2]. Most cancers can eventually progress to metastasis. The occurrence of metastasis is an important indicator of a poor prognosis [27, 28]. Moreover, DM has important significance for TNM (tumor-node-metastasis)

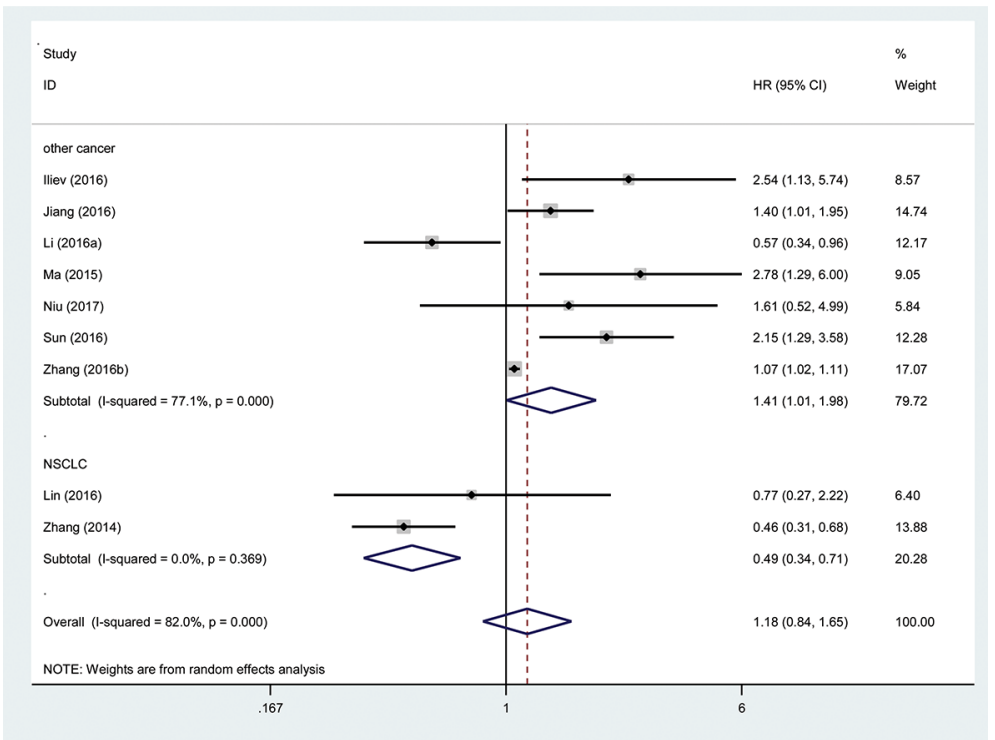

Figure 2: Forest plot showing association between OS and elevated TUG1 expression in the different types of cancer. 
staging. The precise mechanism underlying metastasis remains uncertain. Cancer research hotspot-molecular biomarkers play a critical role in the prediction and treatment of cancer $[29,30]$. It is therefore still necessary and significant to identify new molecular markers to predict tumor metastasis and prognosis.

Recently, genome-wide studies have shown that $80 \%$ of transcription of the mammalian genome is associated with lncRNAs [31], and that lncRNAs play a central role in the regulation of differentiation, cell development and proliferation [32]. Moreover, thanks to the specificity of lncRNA expression during the occurrence and progression of tumors, and the ease with which they can be collected from body fluids and tumor tissues, lncRNAs have the potential to serve as useful biomarkers for the diagnosis and monitoring of tumors [33].
Recent studies have shown that TUG1 plays oncogenic roles during tumorigenesis, and that TUG1 is dysregulated in many tumors, including $\mathrm{HCC}, \mathrm{MIBC}$, ESCC, OC, BC, NSCLC, OSC, SCLC, CRC, RCC and GC [14-26]. In a previous study, Xie et al. found that TUG1 promoted tumorigenesis by inhibiting POU2F1 expression [34]. Wang and others found that the TUG1 was upregulated in $\mathrm{CRC}$, and they further showed that TUG1 knockdown significantly inhibited cell proliferation, migration and invasion of CRC cells in vitro [35]. TUG1 is also a potential oncogene in ESCC that contributes to ESCC cell proliferation and migration [36]. By contrast, TUG1 is downregulated in NSCLC, and high TUG1 expression reportedly correlates with a better prognosis in patients with NSCLC $[20,24]$. These studies suggest TUG1 has prognostic value in cancer patients.

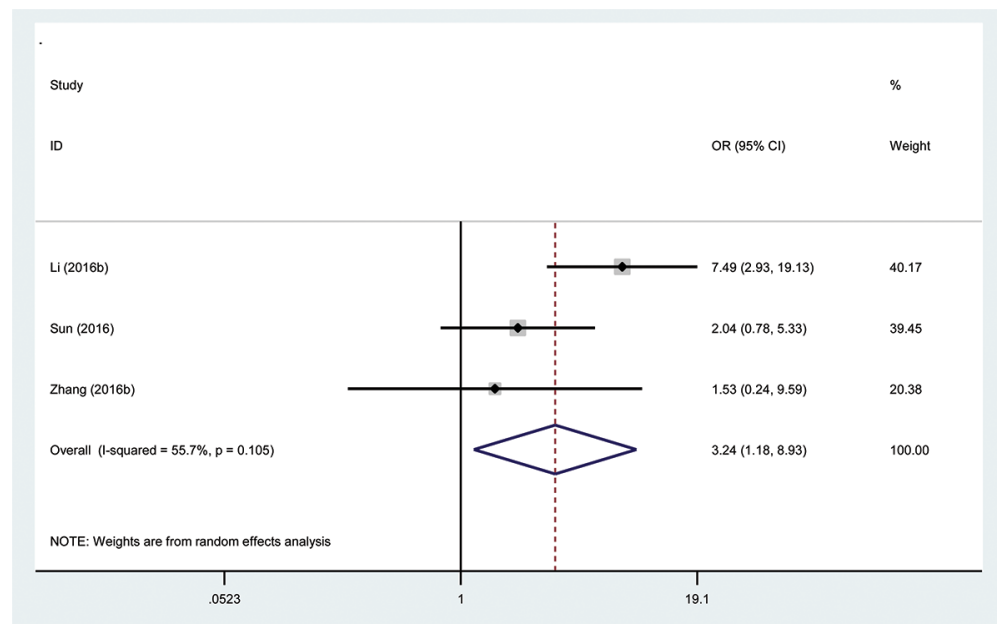

Figure 3: Forest plot showing association between TUG1 expression levels and distant metastasis.

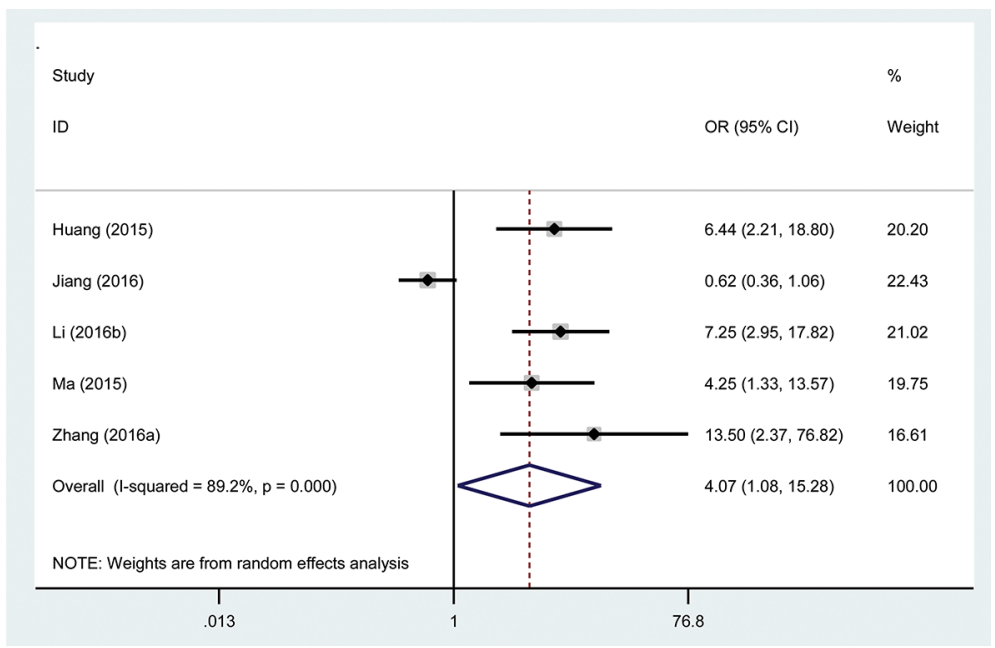

Figure 4: Forest plot showing association between TUG1 expression levels and tumor size. 


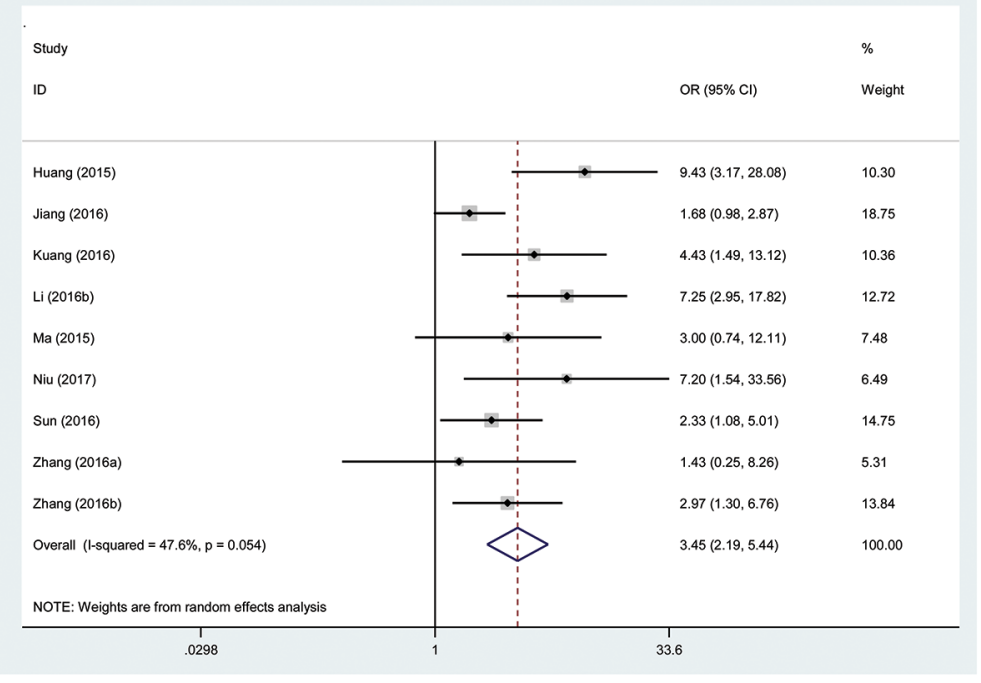

Figure 5: Forest plot showing association between TUG1 expression levels and tumor stage.

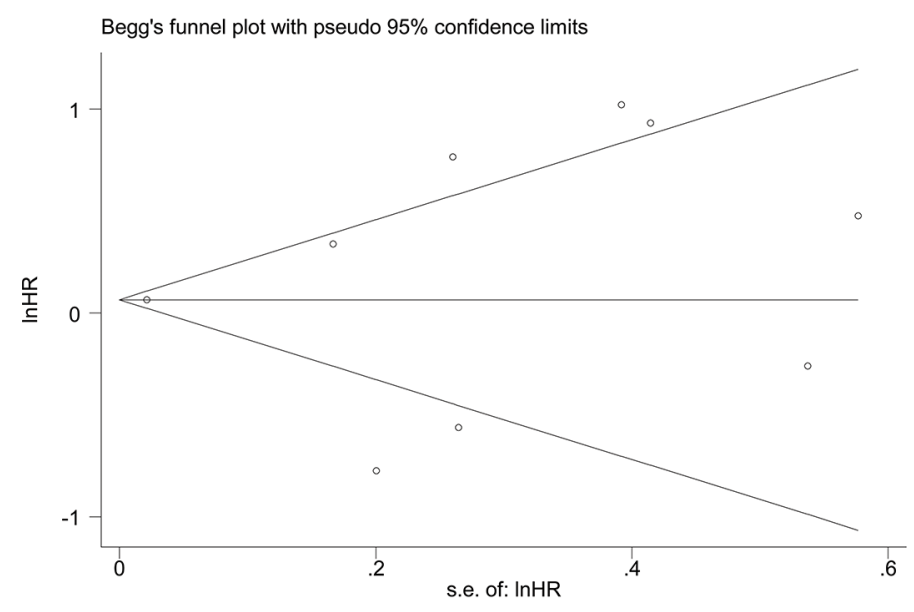

Figure 6: Funnel plot analysis to determine publication bias for the independent role of TUG1 on OS in the different types of cancers.

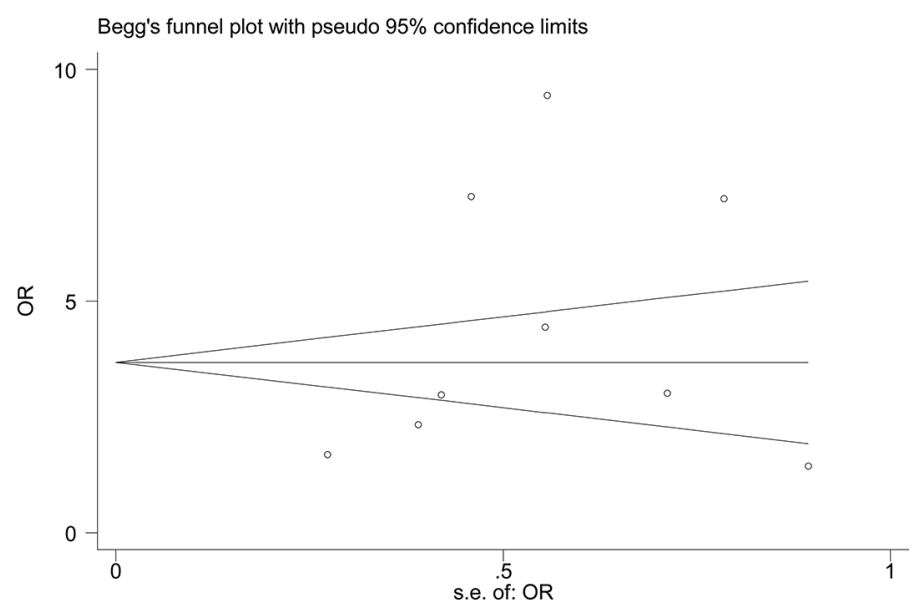

Figure 7: Funnel plot analysis to determine publication bias for the independent role of TUG1 on tumor stage in the different types of cancers. 
Because the utility of TUG1 as a molecular biomarker in human cancer was unclear and contradictory, we conducted this meta-analysis to explore the prognostic value of TUG1 in cancer patients.

One thousand two hundred and seventy-four patients with cancer from 13 eligible studies were collected and analyzed in this study. A random-effects model or fixed-effects model was used depending on the results of heterogeneity analysis. We found that high TUG1 expression may indicate a worse prognosis in cancer patients. By combining HRs from Cox multivariate analyses, there was a significant difference in OS between the high and low TUG1 expression level groups of cancers except NSCLC. Furthermore, statistical analyses revealed that high TUG1 expression in tumor tissues was significantly correlated with DM, advanced tumor stage and large tumor size.

Nevertheless, several limitations must be considered while interpreting the conclusions of the present metaanalysis. First, all but one of the included studies were from China (one study was from Czech Republic); consequently, our data may not be globally representative. Second, the included types and numbers of cancers were small. Third, the criteria for high TUG1 expression differed among the included studies. Therefore, additional well-designed and high-quality studies will be needed to confirm these preliminary findings.

\section{CONCLUSION}

In multiple cancers, high levels of TUG1 expression are significantly correlated with poor OS, DM, large tumor size and advanced tumor stage. TUG1 expression may thus serve as a promising biomarker for predicting prognosis in cancer patients.

\section{MATERIALS AND METHODS}

\section{Literature collection}

According to the standard guidelines of meta-analyses $[37,38]$, a systematic search was performed by two authors independently in the electronic databases of Medline, Pubmed, OVID, and Web of Science for relevant articles that concerned TUG1 as a prognostic biomarker for the survival of cancer patients. The latest search was updated on Jan 11, 2017. We performed literature search by both text word and MeSH strategy with the terms "TUG1", "Taurine up-regulated gene 1", "IncRNA-TUG1", "IncRNA" or " noncoding RNA" or "long intergenic noncoding RNA", "carcinoma" or "neoplasm" or "tumor" or "cancer", "prognostic" or "prognosis", "outcome" or "survival or "recurrence". The strategy was correspondingly adjusted in the different databases. In the retrieval process, we made a manual search using the reference lists of the relevant articles to include eligible studies.

\section{Study selection}

Two researchers evaluated all of the included studies and extracted the data independently. The inclusion criteria were as follows: 1) the relationship between TUG1 expression and survival was measured in multiple human tumors; 2) the expression levels of TUG1 in human tumor tissue were measured, and the patients were grouped according to the expression levels of TUG1; 3) all of the tumors were confirmed by pathological or histological examinations; 4) studies statistically analyzed patient overall survival or pathological parameters such as DM, tumor size and tumor stage, with respect to TUG1 expression.

The following studies were excluded: 1) reviews, letters, editorials, case reports and expert opinions; 2) non-English language and non-human studies; 3) studies without available data; and 4) laboratory studies with the molecular structure and functions of TUG1 only.

\section{Data extraction}

Two reviewers independently extracted and examined the data from the original articles. Disagreements in the literature assessment were resolved through consensus with a third reviewer. The following data were collected: surname of the first author, publication year, country, tumor type, sample size, the number of patients with distant metastasis and high tumor stage, HR and $95 \% \mathrm{CI}$ of elevated TUG1 for OS, reference gene of TUG1, the NOS score, and detection method of TUG1.

The study quality was assessed in accordance with the Newcastle-Ottawa Scale (NOS). Nine items were extracted, and each item scored 1 . The total scores ranged from 0 to 9 . If the scores were $\geq 7$, the study was considered as high quality.

\section{Statistical methods}

Statistical analyses were performed using Stata version 12.0 software. The heterogeneity among different studies was measured by the $\mathrm{Q}$ and $\mathrm{I}^{2}$ tests. A probability value of $\mathrm{I}^{2} \geq 50 \%$, and $\mathrm{P}<0.1$ indicated the existence of significant heterogeneity [39]. A random effects model or fixed effects model was used depending on the results of heterogeneity analysis. If there was a significant heterogeneity among the studies, the random-effects model was adopted. The potential publication bias was assessed by the Begg's funnel plot and Egger's test. Pooled HRs and ORs were extracted from the published data. If the HRs can be obtained directly from the publication, we used crude ones. While the HR and 95\% CI were not directly reported in the studies, survival information was extracted from Kaplan-Meier curves and was used to estimate the HR. The log HR and SE were used to summarize the outcome of overall survival [40]. OR and their 95\% CI were combined to assess the association between TUG1 expression and clinicopathological parameters, including $\mathrm{DM}$, tumor size and tumor stage. 


\section{ACKNOWLEDGMENTS}

This article was supported by Project supported by Foundation of $\mathrm{Wu}$ Jieping foundation for medical science and clinical research (grants No. 320675010071).

\section{CONFLICTS OF INTEREST}

None.

\section{REFERENCES}

1. Ferlay J, Soerjomataram I, Dikshit R, Eser S, Mathers C, Rebelo M, Parkin DM, Forman D, Bray F. Cancer incidence and mortality worldwide: sources, methods and major patterns in GLOBOCAN 2012. Int J Cancer. 2015; 136: E359-E386.

2. Siegel RL, Miller KD, Jemal A. Cancer statistics, 2017. CA Cancer J Clin. 2017; 67: 7-30.

3. Johnsson $\mathrm{P}$, Lipovich L, Grander D, Morris KV. Evolutionary conservation of long non-coding RNAs; sequence, structure, function. Biochim Biophys Acta. 2014; 1840: 1063-1071.

4. Guo H, Wu L, Yang Q, Ye M, Zhu X. Functional lincPOU3F3 is overexpressed and contributes to tumorigenesis in glioma. Gene. 2015; 554: 114-119.

5. Song W, Zou SB. Prognostic role of lncRNA HOTAIR in esophageal squamous cell carcinoma. Clin Chim Acta. 2016; 463: 169-173.

6. Zhou Y, Wang DL, Pang Q. Long noncoding RNA SPRY4-IT1 is a prognostic factor for poor overall survival and has an oncogenic role in glioma. Eur Rev Med Pharmacol Sci. 2016; 20: 3035-3039.

7. Xia M, Yao L, Zhang Q, Wang F, Mei H, Guo X, Huang W. Long noncoding RNA HOTAIR promotes metastasis of renal cell carcinoma by up-regulating histone H3K27 demethylase JMJD3. Oncotarget. 2017; 8: 19795-19802. doi: 10.18632/oncotarget.15047.

8. Cheng N, Li X, Zhao C, Ren S, Chen X, Cai W, Zhao M, Zhang Y, Li J, Wang Q, Zhou C. Microarray expression profile of long non-coding RNAs in EGFR-TKIs resistance of human non-small cell lung cancer. Oncol Rep. 2015; 33: 833-839.

9. Isin M, Dalay N. LncRNAs and neoplasia. Clin Chim Acta. 2015; 444: 280-288.

10. Shao Y, Ye M, Li Q, Sun W, Ye G, Zhang X, Yang Y, Xiao B, Guo J. LncRNA-RMRP promotes carcinogenesis by acting as a miR-206 sponge and is used as a novel biomarker for gastric cancer. Oncotarget. 2016; 7: 3781237824. doi: 10.18632/oncotarget.9336.

11. Fan YH, Fang H, Ji CX, Xie H, Xiao B, Zhu XG. Long noncoding RNA CCAT2 can predict metastasis and poor prognosis: a meta-analysis. Clin Chim Acta. 2017; 466: 120-126.
12. Young TL, Matsuda T, Cepko CL. The noncoding RNA taurine upregulated gene 1 is required for differentiation of the murine retina. Curr Biol. 2005; 15: 501-512.

13. Li Z, Shen J, Chan MT, Wu WK. TUG1: a pivotal oncogenic long non-coding RNA of human cancers. Cell Prolif. 2016; 49: 471-475.

14. Huang MD, Chen WM, Qi FZ, Sun M, Xu TP, Ma P, Shu YQ. Long non-coding RNA TUG1 is up-regulated in hepatocellular carcinoma and promotes cell growth and apoptosis by epigenetically silencing of KLF2. Mol Cancer. 2015; 14: 165 .

15. Iliev R, Kleinova R, Juracek J, Dolezel J, Ozanova Z, Fedorko M, Pacik D, Svoboda M, Stanik M, Slaby O. Overexpression of long non-coding RNA TUG1 predicts poor prognosis and promotes cancer cell proliferation and migration in high-grade muscle-invasive bladder cancer. Tumour Biol. 2016; 37: 13385-13390.

16. Jiang L, Wang W, Li G, Sun C, Ren Z, Sheng H, Gao H, Wang C, Yu H. High TUG1 expression is associated with chemotherapy resistance and poor prognosis in esophageal squamous cell carcinoma. Cancer Chemother Pharmacol. 2016; 78: 333-339.

17. Kuang D, Zhang X, Hua S, Dong W, Li Z. Long non-coding RNA TUG1 regulates ovarian cancer proliferation and metastasis via affecting epithelial-mesenchymal transition. Exp Mol Pathol. 2016; 101: 267-273.

18. Li J, Zhang M, An G, Ma Q. LncRNA TUG1 acts as a tumor suppressor in human glioma by promoting cell apoptosis. Exp Biol Med (Maywood). 2016; 241: 644-649.

19. Li T, Liu Y, Xiao H, Xu G. Long non-coding RNA TUG1 promotes cell proliferation and metastasis in human breast cancer. Breast Cancer. 2016; 24: 535-543. doi: 10.1007/ s12282-016-0736-x.

20. Lin PC, Huang HD, Chang CC, Chang YS, Yen JC, Lee CC, Chang WH, Liu TC, Chang JG. Long noncoding RNA TUG1 is downregulated in non-small cell lung cancer and can regulate CELF1 on binding to PRC2. BMC Cancer. 2016; 16: 583.

21. Ma B, Li M, Zhang L, Huang M, Lei JB, Fu GH, Liu CX, Lai QW, Chen QQ, Wang YL. Upregulation of long non-coding RNA TUG1 correlates with poor prognosis and disease status in osteosarcoma. Tumour Biol. 2016; 37: 4445-4455.

22. Niu Y, Ma F, Huang W, Fang S, Li M, Wei T, Guo L. Long non-coding RNA TUG1 is involved in cell growth and chemoresistance of small cell lung cancer by regulating LIMK2b via EZH2. Mol Cancer. 2017; 16: 5.

23. Sun J, Ding C, Yang Z, Liu T, Zhang X, Zhao C, Wang J. The long non-coding RNA TUG1 indicates a poor prognosis for colorectal cancer and promotes metastasis by affecting epithelial-mesenchymal transition. J Transl Med. 2016; 14: 42.

24. Zhang EB, Yin DD, Sun M, Kong R, Liu XH, You LH, Han L, Xia R, Wang KM, Yang JS, De W, Shu YQ, Wang ZX. P53-regulated long non-coding RNA TUG1 affects cell proliferation in human non-small cell lung cancer, partly 
through epigenetically regulating HOXB7 expression. Cell Death Dis. 2014; 5: e1243.

25. Zhang M, Lu W, Huang Y, Shi J, Wu X, Zhang X, Jiang R, Cai Z, Wu S. Downregulation of the long noncoding RNA TUG1 inhibits the proliferation, migration, invasion and promotes apoptosis of renal cell carcinoma. J Mol Histol. 2016; 47: 421-428.

26. Zhang E, He X, Yin D, Han L, Qiu M, Xu T, Xia R, Xu L, Yin R, De W. Increased expression of long noncoding RNA TUG1 predicts a poor prognosis of gastric cancer and regulates cell proliferation by epigenetically silencing of p57. Cell Death Dis. 2016; 7: e2109.

27. Cho JH, Lee YS, Sun DI, Kim MS, Cho KJ, Nam IC, Kim CS, Kim SY, Park YH, Joo YH. Prognostic impact of lymph node micrometastasis in oral and oropharyngeal squamous cell carcinomas. Head Neck. 2016; 38: E1777-E1782.

28. Li P, Wu F, Zhao H, Dou L, Wang Y, Guo C, Wang G, Zhao D. Analysis of the factors affecting lymph node metastasis and the prognosis of rectal neuroendocrine tumors. Int $\mathrm{J}$ Clin Exp Pathol. 2015; 8: 13331-13338.

29. Mirzaei H, Gholamin S, Shahidsales S, Sahebkar A, Jaafari MR, Mirzaei HR, Hassanian SM, Avan A. MicroRNAs as potential diagnostic and prognostic biomarkers in melanoma. Eur J Cancer. 2016; 53: 25-32.

30. Fan YH, Ye MH, Wu L, Lv SG, Wu MJ, Xiao B, Liao CC, Ji QK, Chai Y, Zhu XG. Overexpression of miR-98 inhibits cell invasion in glioma cell lines via downregulation of IKKepsilon. Eur Rev Med Pharmacol Sci. 2015; 19: 3593-3604.

31. Wang Y, Chen W, Yang C, Wu W, Wu S, Qin X, Li X. Long non-coding RNA UCA1a(CUDR) promotes proliferation and tumorigenesis of bladder cancer. Int J Oncol. 2012; 41: 276-284.

32. Guo H, Hu G, Yang Q, Zhang P, Kuang W, Zhu X, Wu L. Knockdown of long non-coding RNA CCAT2 suppressed proliferation and migration of glioma cells. Oncotarget. 2016; 7: 81806-81814. doi: 10.18632/oncotarget.13242.

33. Qi P, Du X. The long non-coding RNAs, a new cancer diagnostic and therapeutic gold mine. Mod Pathol. 2013; 26: 155-165.

34. Xie CH, Cao YM, Huang Y, Shi QW, Guo JH, Fan ZW, Li JG, Chen BW, Wu BY. Long non-coding RNA TUG1 contributes to tumorigenesis of human osteosarcoma by sponging miR-9-5p and regulating POU2F1 expression. Tumour Biol. 2016; 37: 15031-15041.

35. Wang L, Zhao Z, Feng W, Ye Z, Dai W, Zhang C, Peng J, $\mathrm{Wu} \mathrm{K}$. Long non-coding RNA TUG1 promotes colorectal cancer metastasis via EMT pathway. Oncotarget. 2016; 7: 51713-51719. doi: 10.18632/oncotarget.10563.

36. Xu Y, Wang J, Qiu M, Xu L, Li M, Jiang F, Yin R, Xu L. Upregulation of the long noncoding RNA TUG1 promotes proliferation and migration of esophageal squamous cell carcinoma. Tumour Biol. 2015; 36: 1643-1651.

37. Fan YH, Ji CX, Xu B, Fan HY, Cheng ZJ, Zhu XG. Long noncoding RNA activated by TGF-beta in human cancers: a meta-analysis. Clin Chim Acta. 2017; 468: 10-16.

38. Altman DG, McShane LM, Sauerbrei W, Taube SE. Reporting Recommendations for Tumor Marker Prognostic Studies (REMARK): explanation and elaboration. PLoS Med. 2012; 9: e1001216.

39. Fan YH, Ye MH, Wu L, Wu MJ, Lu SG, Zhu XG. BRAFactivated lncRNA predicts gastrointestinal cancer patient prognosis: a meta-analysis. Oncotarget. 2017; 8: 62956303. doi: 10.18632/oncotarget.14061.

40. Sun DW, Zhang YY, Sun XD, Chen YG, Qiu W, Ji M, Lv GY. Prognostic value of cytokeratin 19 in hepatocellular carcinoma: a meta-analysis. Clin Chim Acta. 2015; 448: 161-169. 